\title{
Understanding Sexual Orientation Identity, Sexual/Romantic Attraction, and Sexual Behavior beyond Western Societies: The Case of Japan ${ }^{1}$
}

\author{
Daiki Hiramori \\ Ph.D. Candidate, Department of Sociology, University of Washington
}

\begin{abstract}
Saori Kamano
Senior Researcher, Department of Population Dynamics Research, National Institute of Population and Social Security Research, Ministry of Health, Labour, and Welfare, Japan
\end{abstract}

\section{$\underline{\text { Abstract }}$ \\ BACKGROUND}

As a growing amount of research examines the impact of sexuality on various demographic outcomes, it becomes important to understand the complex intersections of sexual orientation identity, sexual/romantic attraction, and sexual behavior. However, most previous studies use data

\footnotetext{
1 This work was supported by JSPS KAKENHI Grant Number JP16H03709 "Demography of Sexual Orientation and Gender Identity: Building a Foundation for Research in Japan." The authors would like to thank Jerald R. Herting, Julie Brines, and members of the Gender and Sexuality Graduate Research Cluster at the University of Washington for their helpful suggestions. We would also like to thank Diana Khor of Hosei University for editorial assistance. Direct correspondence to Daiki Hiramori, Department of Sociology, University of Washington, 211 Savery Hall, Box 353340, Seattle, Washington 98195. Email: hiramori@uw.edu.
} 
from Western countries that have particular histories of sexuality, limiting the generalizability of the findings beyond Western societies.

\section{OBJECTIVE}

We describe dimensions of sexuality in Japan, where there has not been any religious authority condemning same-sex behavior and any law prohibiting same-sex relations except for a decade in the late 19th century.

\section{METHODS}

We use data from the "Survey on Diversity of Work and Life, and Coexistence among the Residents of Osaka City," the first population-based survey with detailed questions about multiple aspects of sexuality in Japan, to conduct descriptive analysis.

\section{RESULTS}

More women identify as bisexual or asexual than lesbian. Among the respondents who selected "Don't want to decide, haven't decided"-a category originally created for queer/questioning respondents - as their sexual orientation, the proportion of those who indicated exclusive heterosexuality is higher than expected, raising the possibility that some heterosexual respondents with no heterosexual identity may have mistakenly chosen this category. The data suggest that the population of heterosexual-identified men who have sex with men is small. The prevalence of the asexual population differs by whether sexual orientation identity or sexual/romantic attraction is used to capture this population.

\section{CONTRIBUTION}

Our analysis extends the demography of sexuality by examining unique non-Western data and putting in context the previous findings observed in Western countries. 


\section{Introduction}

Sexual orientation is a social attribute that has an impact on a wide range of issues pertinent to demographic research, such as educational attainment (Mollborn and Everett 2015), earnings (Klawitter 2015), household division of labor (Goldberg, Smith, and Perry-Jenkins 2012), and health (Conron, Mimiage, and Landers 2010). While much research on sexual orientation uses qualitative methods due to the scarcity of quantitative data with information on sexual orientation, there is a growing number of social surveys that include measure(s) of sexual orientation, such as the General Social Survey and the National Survey of Family Growth (Gates 2011). The introduction of sexual orientation measures in these surveys have made it possible to quantitatively examine the impact of sexual orientation on various demographic outcomes mentioned above.

One of the challenges of studying sexual orientation using quantitative methods is the complexity of the concept of sexual orientation, which may be considered to consist of "three basic dimensions: behavior, desire², and identity" (Laumann, Gagnon, Michael, and Michaels 1994:2923). Understanding the complexity of sexual orientation is important because sexual orientation identity $^{3}$ may matter more than sexual attraction and behavior when studying labor market

2 To measure the dimension of "desire," a question on "appeal" that asks whether the respondent thinks having sex with some of the same sex appealing and a question on "attraction" that asks about the gender of those whom the respondent is sexually attracted to is used (Laumann et al. 1994).

3 The Japanese term for "sexual identity" seiteki aidentiti is used to indicate both sexual identity and, albeit to a lesser extent, gender identity, because the Japanese term sei encompasses sex, 
outcomes that are likely to be affected by career plans and openness of one's sexuality at work, while sexual behavior may be more salient when studying health-related issues such as sexually transmitted infections (Badgett 2007) and yet sexual attraction may be important when studying adolescents, who do not necessarily have a stable sexual orientation identity or sexual experience (Saewyc et al. 2004). In other words, the measurement of sexual orientation will likely affect the theorization of the relationship between sexual orientation and the studied outcome. In addition, it is empirically known that the use of different measures for sexual orientation yields distinct results (Mize 2016; Schnabel 2018).

However, almost all of the existing studies exploring the concordance of sexual orientation identity, sexual attraction, and sexual behavior currently use data from North American and Western European countries such as the United States (Mishel 2019) and the United Kingdom (Geary et al. 2018). These societies have distinct histories of sexuality compared to societies with non-Western traditions such as Japan. For example, in Japan, there is historically no "clearcut moral system based on religion" (Lunsing 2001:345) and same-sex relations between men were common in pre-modern Japanese Buddhism, the dominant religion in Japan (Faure 1998); further, there has never existed a law prohibiting same-sex relations except between 1872 and 1882 (Pflugfelder 1999). Thus, the results from previous studies might have stemmed from specific socio-cultural contexts and cannot necessarily be generalized. In order to understand the reality of the complexity of sexuality more comprehensively, it is important to employ data from nonWestern countries and put the previous findings observed in Western countries into context. In

gender, and sexuality. Therefore, this study uses the term "sexual orientation identity" to refer to self-identification of sexual orientations such as heterosexual, lesbian, gay, bisexual, and asexual. 
addition to this, and importantly, many previous studies focus on only certain categories of sexual minorities, such as lesbian, gay, and bisexual, and categories other than these tend to be put together in an "other" category in the analysis.

In view of the limitations of the previous studies, this paper uses data from the "Survey on Diversity of Work and Life, and Coexistence among the Residents of Osaka City" (the Osaka City Residents' Survey, hereafter), the first population-based demographic survey with detailed questions about multiple aspects of sexual orientation in Japan, to descriptively examine the complex intersections between sexual orientation identity, sexual attraction, romantic attraction, and sexual behavior. Unlike other social surveys that ask about sexual orientation, such as the National Survey of Family Growth (Poston and Baumle 2010), the measures of sexuality-related questions employed in this survey are designed to be able to capture the lack of sexual attraction and romantic attraction, in addition to the lack of sexual behavior. Moreover, the question for sexual orientation identity includes categories such as "asexual," “Don't want to decide, haven't decided," and "I do not understand the question," where the last two are utilized to prevent respondents from using "other" as a choice (see Hiramori and Kamano (2020) for more information on the preparatory studies to ask about sexual orientation in representative surveys in the Japanese context). In examining the intersections between different dimensions of sexual orientation, we particularly focus on (1) the general description of dimensions of sexual orientation by gender, (2) patterns of same-sex sexuality, and (3) the asexual spectrum. We also discuss how the historical background in Japan may have an impact on the findings.

\section{$\underline{\text { Extant Research }}$}


In the sociology of sexualities literature, it is known that sexual orientation identity, sexual attraction, and sexual behavior form interrelated but distinct dimensions of sexual orientation (Laumann et al. 1994). For example, $59 \%$ of women and $44 \%$ of men who report any same-sex sexuality in the United States indicate that they have same-sex desire only (i.e. they do not report same-sex behavior or same-sex orientation identity such as homosexual and bisexual), while almost all of those who report same-sex orientation identity indicate that they also have same-sex desire and/or behavior (Laumann et al. 1994). Also, a recent study shows that about $20 \%$ of women and $10 \%$ of men indicate some form of same-sex sexuality, while $6.4 \%$ of women and $3.6 \%$ of men identify as gay, lesbian, or bisexual among U.S. women and men aged 15-45 (Mishel 2019).

Among the studies on multiple aspects of sexual orientation, there is a growing interest in same-sex behavior among straight-identified individuals (Budnick 2016; Silva 2017; Ward 2015). For example, Silva (2017) discusses the role of rural masculinity and heterosexuality in understanding same-sex sexual practices among white, rural, straight-identified men in the United States.

Similarly, there is an increase in the number of quantitative studies on asexualities (Carroll 2019; Poston and Baumle 2010; Rothblum, Krueger, Kittle, and Meyer 2019). Carroll (2019) employs the 2017 Asexual Community Census data to illustrate the diversity of sexual orientation identities that members of the asexual community have as well as other characteristics of the asexual community. Based on a longitudinal epidemiological study conducted on a U.S. population-based sample of lesbian, gay, bisexual and other sexual minority, Rothblum et al. (2019) find that those who identified as asexual tended to be women or gender non-binary, and were less likely to report recent sexual behavior and lower levels of sexual attraction, compared to non-asexual respondents. 


\section{Non-Normative Sexualities in Japan}

In comparing and contrasting the portrait of dimensions of sexuality, it is important to understand the socio-cultural contexts of sexual minorities in Japan. Unlike Christianity, major religions in Japan such as Buddhism and the native Shinto do not have a clear moral system that is hostile to same-sex sexuality or transgenderism (Faure 1998; Mitsuhashi 2008). Research shows that sexual behaviors between men were not uncommon in pre-modern Japan (Pflugfelder 1999). Similarly, there is a long tradition of (mainly male-to-female) cross-dressing in Japanese history (Mitsuhashi 2008) ${ }^{4}$. The public discourses regarding non-normative sexuality and gender became hostile only when Japan began to be incorporated into the modern world in the late 19th century (Leupp 1995). Nevertheless, the law prohibiting anal sex between men existed only between 1872 and 1882, and this was the only law prohibiting same-sex sexual behavior in Japan (Pflugfelder 1999).

After the defeat of Japan in World War II, the term gei, or gay, was introduced via gay men in the Allied occupation forces (McLelland 2005). In Japan, however, this term first came to be understood as effeminate gay "men who displayed transgender characteristics and worked in the entertainment world" (McLelland 2005:104). Although the disassociation of same-sex

4 It should be noted that the Japanese society has been tolerant of non-normative sexualities "only as far as they are kept outside the sphere of daily normality and do not start questioning the line of demarcation or threatening the normal, existing system of society and family that has been supplemented, and therefore supported, by the abnormal" (Shimizu 2007:507). Similarly, scholars have argued that the overemphasis of the tolerance of same-sex sexuality among men in Japan obscures the issues of lesbian invisibility and gender inequality in Japan (Khor 2010). 
sexuality from transgenderism started gradually in the 1980s, with the rise of the lesbian and gay movement in Japan and the term gei started to be used in a similar way as in English (McLelland 2005), same-sex sexuality is rarely discussed as a "lifestyle" or "rights" even in gay media in Japan while the mainstream media still conflate same-sex sexuality with transsexuality in contemporary Japan. All this makes it difficult for Japanese gay men to develop a stable sexual orientation identity as "gay" (McLelland 2000). Similarly, sociologists of sexuality in Japan argue that the fact that there was less explicit legal and religious discrimination against sexual minorities in Japan may have made it difficult for them to develop a definite sexual minority identity and to form collective mobilizations seen in countries such as the United States (Kazama and Kawaguchi 2010).

Developing a sexual orientation identity may be even more difficult for lesbians than gay men. Lesbians are largely invisible in mainstream Japanese society, being subsumed under the category of "homosexual people" that actually is defined by gay men's sexuality (Horie 2006). It was not uncommon to hear the claim that "there are no lesbians in Japan" until recently (Kamano 2005). Even when media attention on sexual and gender minorities has increased since 2015, the coverage of lesbians is less common than that of gay men or transgender people.

Discussing the reasons why, unlike Western countries, there are more female-to-male (FtM) transgender people than male-to-female (MtF) transgender people in Japan (Oshima and Sato 2016) ${ }^{5}$, Mitsuhashi (2012) points out that the Japanese Gender Identity Disorder (GID)

5 De Cuypere et al. (2007) review previous studies on the prevalence of transgender population in Western European countries as well as the United States, Australia, and Singapore, and report that all of the research shows that there are more MtF transgender people than FtM transgender people. The male/female ratios are estimated to be between 2.5:1 and 6.1:1 (De Cuypere et al. 2007). In 
Special Law may have induced some lesbians to identify as FtM transgender. Also, the invisibility of women same-sex sexuality in Japanese society (Horie 2015; Kamano 2005) may encourage cisgender lesbians to resort to identifying as transgender and/or non-binary. Mitsuhashi (2012) observes that the gay community and the MtF community were already segregated before the late 1990s, when the concept of GID became widely known in Japan, while the lesbian community and the FtM community were less segregated.

As of 2020 , there is no national law protecting sexual and gender minorities from discrimination in Japan; Tokyo and Ibaraki are currently the only two prefectures with an antidiscriminatory ordinance based on sexual orientation and gender identity (Human Rights Watch 2018; Japan Times 2019). Regarding attitudes toward same-sex sexuality today, Japan does not differ significantly from the United States in terms of the overall level of societal acceptance, and same-sex sexuality is actually more accepted in Japan than in other East Asian countries such as South Korea and China (Pew Research Center 2013).

\section{Data and Methods}

This study uses data from the "Survey on Diversity of Work and Life, and Coexistence among the Residents of Osaka City," conducted by the research project "Demography of Sexual Orientation and Gender Identity: Building a Foundation for Research in Japan ${ }^{6}$," with the

Poland, however, Godlewski (1988), as well as Dulko and Imielinski (2004), reports that there are more FtM transgender people than MtF transgender people, a similar pattern to the trend in Japan.

${ }^{6}$ The first author is a research collaborator and the second author is the principal investigator of this project. 
cooperation of Osaka City. The survey period was between January 16, 2019 (mailed) and January 28, but it was extended to February 4 via a reminder postcard, and responses were considered valid if they arrived by March 7. The questionnaire was sent by postal mail to 15,000 people aged 18 to 59 who resided in Osaka City, the third-largest city in Japan (randomly sampled from the Basic Resident Register as of October 1, 2018), and 4,294 were returned by mail or responded online. The number of valid responses was 4,285, and the valid response rate was $28.6 \%$ (see Kamano et al. (2019) for more details of the Osaka City Residents' Survey).

In most of the analyses below, we focus on cisgender (non-transgender) respondents because of the indeterminate relationship between sex assigned at birth, gender identity, and sexual orientation among transgender people. Some transgender people report the shifts in their sexual orientation after social or medical transition, while other transgender people identify with the same sexual orientation after transition (Galupo, Henise, and Mercer 2016). The questions related to gender identity are as follows: (Step 1) "Circle your sex. [sex on the family register or birth certificate at birth] (Circle one)" 1. Male 2. Female (Step 2) "Do you consider that your current gender is the same as your sex at birth (The one you circled above)? Circle all that apply. If you circle 2 and/or 3 on the left, please answer your current recognition." [Left] 1. Same as sex at birth 2. Different gender 3. Have a sense of discomfort (Step 3) [Right] "The gender that is closest to your current recognition: (Circle one)" 1. Man 2. Woman 3. Other (please specify:___ Among the survey respondents, the number of people whose current gender identity differs from sex at birth or whose current gender identity is "other" was $32(0.7 \%)$. The number of people whose sex at birth is "male" and current identity is "woman" (6 people) or "other" (6 people) was $12(0.3 \%)$, and the number of people whose sex at birth is "female" and current identity is "man" (4 people) or "other" (16 people) was $20(0.5 \%)$. These 12 assigned males at birth and 20 assigned females 
at birth are classified as transgender for the purpose of this paper and are not included in most of the analyses. Excluding the analysis of asexualities, the final sample of the analyses reported in this paper is 2,497 cisgender women and 1,742 cisgender men. For the analysis of the dimensions of asexualities, we employ the full sample, viz. the sample including transgender people $(2,517$ females at birth and 1,754 males at birth), because the issue of how transgender people consider their sexual orientation is not relevant when discussing asexualities.

\section{Measures of Sexual Orientation}

To measure multiple aspects of sexual orientation, (1) sexual orientation identity, (2) sexual attraction, (3) romantic attraction, and (4) sexual behavior were asked in the survey. Unlike previous studies that focus on sexual orientation identity, sexual attraction, and sexual behavior (Laumann et al. 1994; Mishel 2019), our measures of sexual orientation include romantic attraction as an additional dimension of sexual orientation because community-based surveys on sexual and gender minorities in Japan have typically used romantic attraction as the indicator of sexual orientation (Nijiiro Diversity and the Center for Gender Studies at International Christian University 2020). Similarly, marketing surveys on sexual and gender minority issues in Japan often define sexual orientation as "the gender of people you are attracted to" (Dentsu 2019)7.

${ }^{7}$ A similar focus on the romantic aspect of sexuality is observed in the asexual community in Japan which historically utilized a restricted definition of asexuality that is equivalent to "aromantic asexual" in the English language (i.e. someone with neither sexual attraction nor romantic attraction). For the purpose of this paper, we use the term "asexual" as it is typically used in the English language. 


\section{(1) Sexual Orientation Identity}

For sexual orientation identity, we use the following question: "Please circle the number that you think is closest to you. (Circle one)." The choices are "heterosexual, that is, not gay, lesbian, etc. [those who have sexual/romantic feelings only for different-sex people]," "gay, lesbian, homosexual [those who have sexual/romantic feelings only for same-sex people]," "bisexual [those who have sexual/romantic feelings for both men and women]," "asexual [those who do not have sexual/romantic feelings for anyone]," "Don't want to decide, haven't decided," and "I do not understand the question." Given that the use of the choices such as "other" and "unsure" is not recommended (SMART 2009), we include "Don’t want to decide, haven't decided" for those whose sexual orientation identity is questioning, queer, or other sexual minority categories, and "I do not understand the question" for supposedly heterosexual respondents who do not understand the term "heterosexual" (see Hiramori and Kamano (2020) for findings from the focus groups and the pilot survey on asking about sexual orientation in population-based surveys in the Japanese context).

\section{(2) Sexual Attraction}

For sexual attraction, we use the following questions: "For each of the following from (1) to (3), please circle the numbers closest to you from 1 to 6 , concerning your experience (A) up until now and (B) in the last five years. (Circle one for each). [...] (2) People you are sexually attracted to." The choices are "I have never been sexually attracted to either men or women," "exclusively men," "mostly men," "men and women, equally," "mostly women," and "exclusively women." Because this survey is a mail survey and response options cannot be altered by the respondent's gender, we list "I have never been sexually attracted to either 
men or women" as the first choice so that careless respondents who are men, for example, do not mistakenly choose "exclusively men," which may inflate the proportion of men who are sexually attracted to men (Hiramori and Kamano 2020). For the purpose of this analysis, we use lifetime sexual attraction to broaden the scope of non-heterosexual sexual attraction as much as possible.

(3) Romantic Attraction

For romantic attraction, we use the following questions: "For each of the following from (1) to (3), please circle the numbers closest to you from 1 to 6 , concerning your experience (A) up until now and (B) in the last five years. (Circle one for each). (1) People you have romantic feelings for." The choices are "I have never had romantic feelings for either men or women.," "exclusively men," "mostly men," "men and women, equally," "mostly women," and "exclusively women." For the purpose of this analysis, we use lifetime romantic attraction to broaden the scope of non-heterosexual romantic attraction as much as possible.

\section{(4) Sexual Behavior}

For sexual behavior, we use the following questions: "For each of the following from (1) to (3), please circle the numbers closest to you from 1 to 6 , concerning your experience (A) up until now and (B) in the last five years. (Circle one for each). [...] (3) People you have sex with." The choices are "I have never had sex.," "exclusively men," "mostly men," "men and women, equally," "mostly women," and "exclusively women." For the purpose of this analysis, we use lifetime sexual behavior to broaden the scope of non-heterosexual sexual behavior as much as possible. 


\section{Analytic Strategy}

First, we start the analysis by describing the relationship between dimensions of sexual orientation by gender. In particular, we provide descriptive statistics of sexual orientation identity by gender, intersections between sexual orientation identity and sexual attraction, intersections between sexual orientation identity and romantic attraction, and intersections between sexual orientation identity and sexual behavior. Second, we focus on various forms of same-sex sexuality, measured by sexual orientation identity, sexual attraction, romantic attraction, and sexual behavior. Third, we shift our focus to the asexuality spectrum and report the proportion of those who identify as asexual, those who have neither romantic attraction nor sexual attraction (those who may be classified as aromantic asexual), and the proportion of those who have romantic attraction but do not have sexual attraction (those who may be classified as romantic asexual), as well as sexual behavior among those who do not have sexual attraction and those who have sexual attraction. The extremely small sample size of sexual minorities in this study means that statistical tests may not be appropriate. Therefore, we avoid using the standard methods of statistical inferences and focus on descriptive patterns.

\section{$\underline{\text { Results }}$}

Sexual Orientation Identity by Gender

Table 1 shows the percentages of respondents' sexual attraction, romantic attraction, and sexual behavior by sexual orientation identity and gender. Looking at sexual orientation identity by gender (see the row "Total"), a great majority of the respondents chose "heterosexual" (83.3\% of women and $85.0 \%$ of men). For non-heterosexual categories, $0.2 \%$ of women and $1.3 \%$ of men reported that they were "gay, lesbian, or homosexual." Compared to other previous studies in the 
United States and other Western countries (Gates 2011), the percentage of women who identify as lesbian is very low, and this result indicates that women are less likely than men to identify as "gay, lesbian, or homosexual." On the other hand, $1.6 \%$ of women and $1.0 \%$ of men reported themselves as "bisexual," and women were more likely to identify as "bisexual" than men. Also, 1.0\% of women and $0.2 \%$ of men reported that they were "asexual," indicating that women are more likely than men to identify as "asexual." In addition, the result shows that there are more asexual women respondents than lesbian respondents in this survey $(1.0 \%$ and $0.2 \%$, respectively). Another interesting result is that $6.2 \%$ of women and $3.1 \%$ of men choose "Don't want to decide, haven't decided." Considering that this category was originally created to capture sexual minorities who do not consider themselves as lesbian, gay, bisexual, or asexual, these percentages are unexpectedly high. However, as we will discuss below, there is a possibility that many of those who selected this category are heterosexual respondents who did not understand the question properly. Also, $6.8 \%$ of women and $8.6 \%$ of men selected "I do not understand the question" and $1.0 \%$ of women and $0.9 \%$ of men did not answer this question.

\section{Intersections between Sexual Orientation Identity and Sexual Attraction}

Table 1 also shows the association between sexual orientation identity and sexual attraction (see the rows located under the category "Sexual Attraction"). Among women who identified as "heterosexual," $94.0 \%$ reported that they were sexually attracted to men exclusively, $2.9 \%$ reported that they were sexually attracted to men mostly, $0.2 \%$ reported that they were sexually attracted to men and women equally, and $2.1 \%$ reported that they had never been sexually attracted to either men or women. Among men who identify as "heterosexual," $97.0 \%$ reported that they were sexually attracted to women exclusively, $1.5 \%$ reported that they were sexually 
attracted to women mostly, $0.3 \%$ reported that they were sexually attracted to men exclusively, and $0.8 \%$ reported that they had never been sexually attracted to either men or women. Overall, the results for those who identified as "heterosexual" indicate that respondents who are men tend to report exclusive sexual attraction to people of the opposite sex, while more women respondents tend to report that they are sexually attracted to people of the opposite sex mostly than respondents who are men. Similarly, more women respondents reported no lifetime sexual attraction than men respondents.

For those who have a sexual orientation identity other than heterosexual, the following observations can be made. Among women who identified as "gay, lesbian, or homosexual," the majority of the respondents reported exclusive same-sex sexual attraction, although there were only five respondents in total. A similar pattern is found among men who identified as "gay, lesbian, or homosexual." Among men who identified as "gay, lesbian, or homosexual," a small number of respondents also reported that they were sexually attracted to men mostly. For those who identified as "gay, lesbian, or homosexual," none reported that they had never been attracted to either men or women. Among women who identified as "bisexual," a quarter to a third of the respondents reported that they were sexually attracted to men exclusively, sexually attracted to men mostly, or sexually attracted to men and women equally. Also, about $13 \%$ of them reported that they were sexually attracted to women mostly and about $8 \%$ of them reported that they had never sexually attracted to either men or women. On the other hand, among men who identified as "bisexual," fewer respondents than women respondents reported that either they were sexually attracted to people of the opposite sex mostly and more respondents than women respondents reported that they were sexually attracted to men and women equally. Also, none of the bisexual-identified men in the sample reported that they had never been sexually attracted to either men or women. Among 
women respondents who identified as "asexual," about half of them reported no lifetime sexual attraction and the remaining half reported some kind of sexual attraction. Among three asexualidentified respondents who are men, one respondent reported exclusive opposite-sex sexual attraction and two respondents reported no lifetime sexual attraction.

Among women respondents who selected "Don't want to decide, haven't decided," about $40 \%$ of them reported that they were sexually attracted to men exclusively, about $30 \%$ of them reported that they were sexually attracted to men mostly, about $7 \%$ reported that they were sexually attracted to men and women equally, about $1 \%$ reported that they were sexually attracted to women mostly, and about $17 \%$ reported that they had never been sexually attracted to either men or women. Compared to women respondents who selected "Don't want to decide, haven't decided yet," respondents who are men were more likely to report exclusive opposite-sex sexual attraction (about $76 \%$ ). About $20 \%$ of them also reported that they were sexually attracted to women mostly. Among those who selected "I do not understand the question," the majority reported exclusive opposite-sex sexual attraction among both women and men and about $4-5 \%$ of them reported that they were sexually attracted to people of the opposite sex mostly. Also, about $6-7 \%$ of them reported that they had never been sexually attracted to either men or women. Overall, $88 \%$ of women and $93 \%$ of men reported exclusive opposite-sex sexual attraction, $7 \%$ of women and $5 \%$ reported non-exclusively heterosexual sexual attraction, and $4 \%$ of women and $1 \%$ of men reported that they had never been sexually attracted to either men or women.

Intersections between Sexual Orientation Identity and Romantic Attraction

For the association between sexual orientation identity and romantic attraction, the results are mostly similar to those of the intersection of sexual orientation identity and sexual attraction, 
but a few differences are also observed. Among men identifying as "gay, lesbian, or homosexual," about $46 \%$ of them reported that they were romantically attracted to men mostly and $55 \%$ of them reported that they were romantically attracted to men exclusively (for sexual attraction, the numbers were $14 \%$ and $86 \%$, respectively). Also, among asexual-identified women, $38 \%$ of them reported that they had never had romantic feelings for either men or women, while $54 \%$ of them reported that they had never been sexually attracted to either men or women. For the respondents who selected "Don't want to decide, haven't decided," about 50\% of women respondents reported that they were sexually attracted to men exclusively and about $75 \%$ of men respondents reported that they were sexually attracted to women exclusively, indicating that the majority of those who selected this category show exclusive opposite-sex sexual and romantic attraction. Overall, $90 \%$ of women and $92 \%$ of men reported exclusive opposite-sex romantic attraction, $7 \%$ of women and $5 \%$ reported non-exclusively heterosexual romantic attraction, and $3 \%$ of women and $2 \%$ of men reported that they had never had romantic feelings for either men or women.

\section{Intersections between Sexual Orientation Identity and Sexual Behavior}

The results of the association between sexual orientation identity and sexual behavior are also similar to the results of the relationship between sexual orientation identity and sexual attraction, but there are a couple of notable differences. Among those who identified as "heterosexual," the percentages of those who have never had sex are higher than the percentages of those who reported that they had never been sexually attracted to either men or women and those who reported that they had never had romantic feelings for either men or women. Also, among those who identified as "bisexual," the percentages of respondents who reported that people with whom they had sex were exclusively people of the opposite sex were higher than the 
percentages of respondents who reported that they were sexually attracted to people of the opposite sex exclusively (women: $51.3 \%$ vs. $23.1 \%$, men: $35.3 \%$ vs. $23.5 \%$ ). On the other hand, while $23.1 \%$ of bisexual-identified women and $41.2 \%$ reported that they were sexually attracted to men and women equally, $7.7 \%$ of bisexual-identified women and $17.6 \%$ of bisexual-identified men reported that people with whom they had sex were men and women equally. In addition, while the results of sexual attraction and romantic attraction among those who selected "Don't want to decide, haven't decided" were somewhat similar to the results among those who identified as "heterosexual," those who selected "Don't want to decide, haven't decided" are far more likely than those who identify as "heterosexual" to report that they have never had sex ( $22.1 \%$ of women and $13.0 \%$ of men). This pattern is also seen among those who selected "I do not understand the question," albeit to a lesser extent ( $9.4 \%$ of women and $12.0 \%$ of men), suggesting that prior sexual experience may have an impact on whether or not one chooses "heterosexual" as an identity for those whose sexual and romantic attraction may be heterosexual. 
Table 1 Sexual attraction, romantic attraction, and sexual behavior (lifetime) by sexual orientation identity among cisgender women and men (\%): Osaka City Residents' Survey, 2019

\begin{tabular}{|c|c|c|c|c|c|c|c|c|c|c|c|c|c|c|c|c|}
\hline & \multicolumn{2}{|c|}{ Heterosexual } & \multicolumn{2}{|c|}{$\begin{array}{l}\text { Gay, lesbian } \\
\text { homosexual }\end{array}$} & \multicolumn{2}{|c|}{ Bisexual } & \multicolumn{2}{|c|}{ Asexual } & \multicolumn{2}{|c|}{$\begin{array}{l}\text { Don't want to } \\
\text { decide, haven't } \\
\text { decided }\end{array}$} & \multicolumn{2}{|c|}{$\begin{array}{l}\text { I do not } \\
\text { understand } \\
\text { the question. }\end{array}$} & \multicolumn{2}{|l|}{ N/A } & \multicolumn{2}{|l|}{ Total } \\
\hline & $\mathrm{W}$ & $\mathrm{M}$ & $\mathrm{W}$ & $\mathrm{M}$ & $\mathrm{W}$ & $\mathrm{M}$ & $\mathrm{W}$ & $\mathrm{M}$ & $\mathrm{W}$ & $\mathrm{M}$ & $\mathrm{W}$ & $\mathrm{M}$ & $\mathrm{W}$ & $\mathrm{M}$ & $\mathrm{W}$ & $\mathrm{M}$ \\
\hline $\mathrm{n}$ & 2,080 & 1,481 & 5 & 22 & 39 & 17 & 24 & 3 & 154 & 54 & 171 & 150 & 24 & 15 & 2,497 & 1,742 \\
\hline Total (\%) & 83.3 & 85.0 & 0.2 & 1.3 & 1.6 & 1.0 & 1.0 & 0.2 & 6.2 & 3.1 & 6.8 & 8.6 & 1.0 & 0.9 & 100.0 & 100.0 \\
\hline \multicolumn{17}{|l|}{ Sexual Attraction } \\
\hline Exclusively OS & 94.0 & 97.0 & 0.0 & 0.0 & 23.1 & 23.5 & 37.5 & 33.3 & 40.3 & 75.9 & 80.7 & 80.7 & 45.8 & 66.7 & 87.5 & 92.7 \\
\hline Mostly OS & 2.9 & 1.5 & 20.0 & 0.0 & 33.3 & 17.6 & 4.2 & 0.0 & 33.1 & 20.4 & 4.1 & 4.7 & 4.2 & 0.0 & 5.4 & 2.5 \\
\hline Equal & 0.2 & 0.0 & 0.0 & 0.0 & 23.1 & 41.2 & 4.2 & 0.0 & 6.5 & 1.9 & 1.2 & 1.3 & 0.0 & 0.0 & 1.1 & 0.6 \\
\hline Mostly SS & 0.0 & 0.0 & 0.0 & 13.6 & 12.8 & 17.6 & 0.0 & 0.0 & 1.3 & 0.0 & 0.0 & 0.0 & 0.0 & 0.0 & 0.3 & 0.3 \\
\hline Exclusively SS & 0.0 & 0.3 & 80.0 & 86.4 & 0.0 & 0.0 & 0.0 & 0.0 & 0.0 & 0.0 & 0.0 & 0.0 & 0.0 & 0.0 & 0.2 & 1.3 \\
\hline No attraction & 2.1 & 0.8 & 0.0 & 0.0 & 7.7 & 0.0 & 54.2 & 66.7 & 16.9 & 1.9 & 6.4 & 6.7 & 0.0 & 0.0 & 3.8 & 1.4 \\
\hline N/A & 0.8 & 0.4 & 0.0 & 0.0 & 0.0 & 0.0 & 0.0 & 0.0 & 1.9 & 0.0 & 7.6 & 6.7 & 50.0 & 33.3 & 1.8 & 1.2 \\
\hline \multicolumn{17}{|l|}{ Romantic Attraction } \\
\hline Exclusively OS & 94.9 & 96.4 & 0.0 & 0.0 & 20.5 & 23.5 & 45.8 & 66.7 & 50.6 & 74.1 & 80.7 & 83.3 & 45.8 & 66.7 & 88.9 & 92.3 \\
\hline Mostly OS & 2.8 & 1.4 & 20.0 & 0.0 & 46.2 & 23.5 & 16.7 & 0.0 & 32.5 & 20.4 & 4.7 & 5.3 & 0.0 & 0.0 & 5.6 & 2.5 \\
\hline Equal & 0.0 & 0.1 & 0.0 & 0.0 & 23.1 & 41.2 & 0.0 & 0.0 & 4.5 & 1.9 & 1.2 & 1.3 & 8.3 & 0.0 & 0.8 & 0.6 \\
\hline Mostly SS & 0.0 & 0.1 & 0.0 & 45.5 & 7.7 & 11.8 & 0.0 & 0.0 & 0.6 & 0.0 & 0.0 & 0.0 & 0.0 & 0.0 & 0.2 & 0.7 \\
\hline Exclusively SS & 0.0 & 0.2 & 80.0 & 54.5 & 0.0 & 0.0 & 0.0 & 0.0 & 0.0 & 0.0 & 0.0 & 0.0 & 0.0 & 0.0 & 0.2 & 0.9 \\
\hline No attraction & 1.5 & 1.6 & 0.0 & 0.0 & 2.6 & 0.0 & 37.5 & 33.3 & 10.4 & 3.7 & 6.4 & 4.0 & 0.0 & 0.0 & 2.7 & 1.9 \\
\hline N/A & 0.7 & 0.3 & 0.0 & 0.0 & 0.0 & 0.0 & 0.0 & 0.0 & 1.3 & 0.0 & 7.0 & 6.0 & 45.8 & 33.3 & 1.6 & 1.1 \\
\hline \multicolumn{17}{|l|}{ Sexual Behavior } \\
\hline Exclusively OS & 92.8 & 93.5 & 0.0 & 0.0 & 51.3 & 35.3 & 33.3 & 0.0 & 66.2 & 79.6 & 81.3 & 82.0 & 41.7 & 66.7 & 88.5 & 90.0 \\
\hline Mostly OS & 0.8 & 0.5 & 40.0 & 0.0 & 20.5 & 23.5 & 8.3 & 0.0 & 5.8 & 3.7 & 1.2 & 0.0 & 0.0 & 0.0 & 1.6 & 0.8 \\
\hline Equal & 0.0 & 0.0 & 0.0 & 0.0 & 7.7 & 17.6 & 0.0 & 0.0 & 1.3 & 1.9 & 0.0 & 0.7 & 0.0 & 0.0 & 0.2 & 0.3 \\
\hline Mostly SS & 0.0 & 0.1 & 20.0 & 13.6 & 7.7 & 5.9 & 0.0 & 0.0 & 1.3 & 0.0 & 0.0 & 0.0 & 0.0 & 0.0 & 0.2 & 0.3 \\
\hline Exclusively SS & 0.0 & 0.2 & 40.0 & 86.4 & 7.7 & 0.0 & 4.2 & 0.0 & 0.0 & 1.9 & 0.0 & 0.0 & 0.0 & 0.0 & 0.2 & 1.3 \\
\hline No sex & 4.9 & 5.2 & 0.0 & 0.0 & 5.1 & 17.6 & 50.0 & 100.0 & 22.1 & 13.0 & 9.4 & 12.0 & 0.0 & 0.0 & 6.7 & 6.2 \\
\hline N/A & 1.4 & 0.5 & 0.0 & 0.0 & 0.0 & 0.0 & 4.2 & 0.0 & 3.2 & 0.0 & 8.2 & 5.3 & 54.2 & 33.3 & 2.5 & 1.1 \\
\hline
\end{tabular}

Notes: W is Women; M is Men; OS is Opposite Sex; SS is Same Sex. 


\section{Forms of Same-Sex Sexuality}

Figures 1.1 through 3.2 use Venn diagrams to show how (A) sexual attraction, (B) romantic attraction, (C) sexual behavior, and (D) sexual orientation identity shape various forms of same-sex sexuality. For sexual attraction, those who are sexually attracted to (1) people of the opposite sex mostly, (2) men and women, equally, (3) people of the same sex mostly, and (4) people of the same sex exclusively are included. For romantic attraction, those who have romantic feelings for (1) people of the opposite sex mostly, (2) men and women, equally, (3) people of the same sex mostly, and (4) people of the same sex exclusively are included. For sexual behavior, those who have sex with (1) people of the opposite sex mostly, (2) men and women, equally, (3) people of the same sex mostly, and (4) people of the same sex exclusively are included. For sexual orientation identity, those who selected "gay, lesbian, homosexual" or "bisexual" are included. Using these criteria yields 244 cisgender women $(9.8 \%$ of the total 2,497$)$ who reported any lifetime same-sex sexuality and 109 cisgender men $(6.3 \%$ of the total 1,742$)$ who reported any lifetime same-sex sexuality.

Figures 1.1 and 1.2 show that the proportion of people who report same-sex sexuality in all dimensions, viz. the same-sex attraction, same-sex behavior, and same-sex sexual orientation identity, is low, particularly among women (women: 9.0\%, men: $26.6 \%$ ). This pattern does not change when sexual attraction is replaced by romantic attraction (women: $8.6 \%$, men: $27.5 \%$, shown in Figures 2.1 and 2.2). In addition, regardless of the choice of the three main dimensions selected in the figures, many people among those who reported any same-sex sexuality only reported same-sex sexual/romantic attraction (women: 65.2\%, men: 48.6\%, shown in Figures 3.1 and 3.2), which shows a similar pattern found in Laumann et al's (1994) study (women: 59\%, men: $44 \%$ ). On the other hand, Figure 1.2 shows that only $6.4 \%$ of men who reported any same-sex 
sexuality reported same-sex sexual behavior among men, which is much lower than the percentage reported in Laumann et al's (1994) study (22\%), suggesting that the population of heterosexualidentified men who have sex with men may be smaller in Japan.

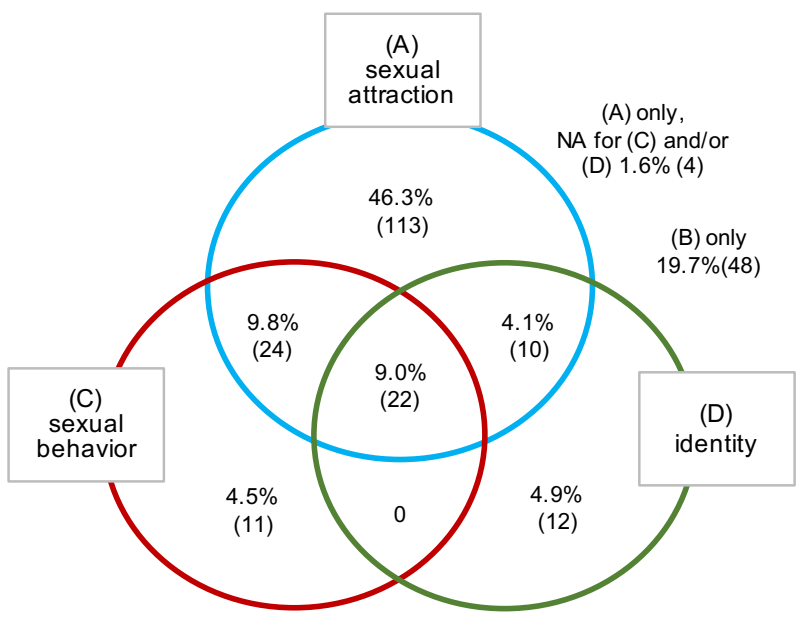

Figure 1.1 Interrelation of components of same-sex sexuality among cisgender women, Osaka City Residents' Survey, 2019: (A) sexual attraction, (C) sexual behavior, and (D) sexual orientation identity for 244 cisgender women $(9.8 \%$ of the total 2497$)$ who report same-sex sexuality in any of the four components $(A, B, C$ or D)

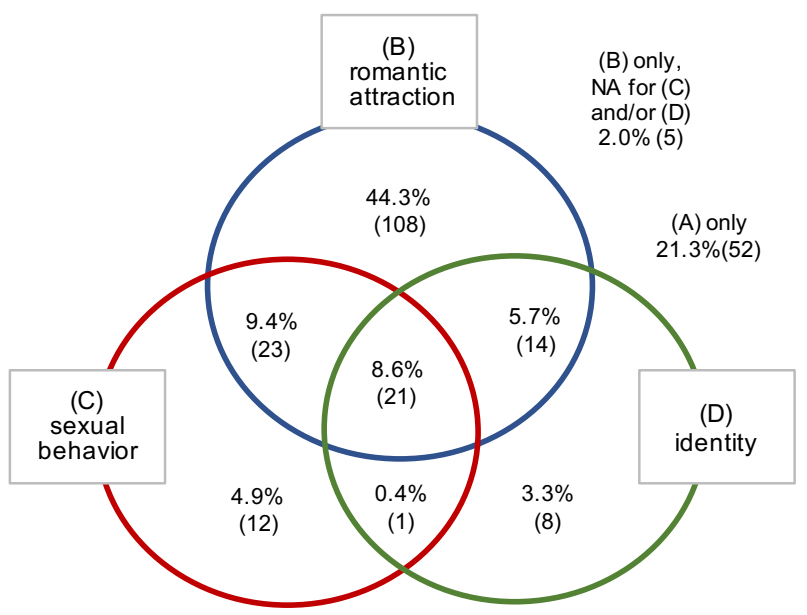

Figure 2.1 Interrelation of components of same-sex sexuality among cisgender women, Osaka City Residents' Survey, 2019: (B) romantic attraction, (C) sexual behavior, and (D) sexual orientation identity for 244 cisgender women ( $9.8 \%$ of the total 2497) who report same-sex sexuality in any of the four components $(\mathrm{A}, \mathrm{B}, \mathrm{C}$ or $\mathrm{D})$

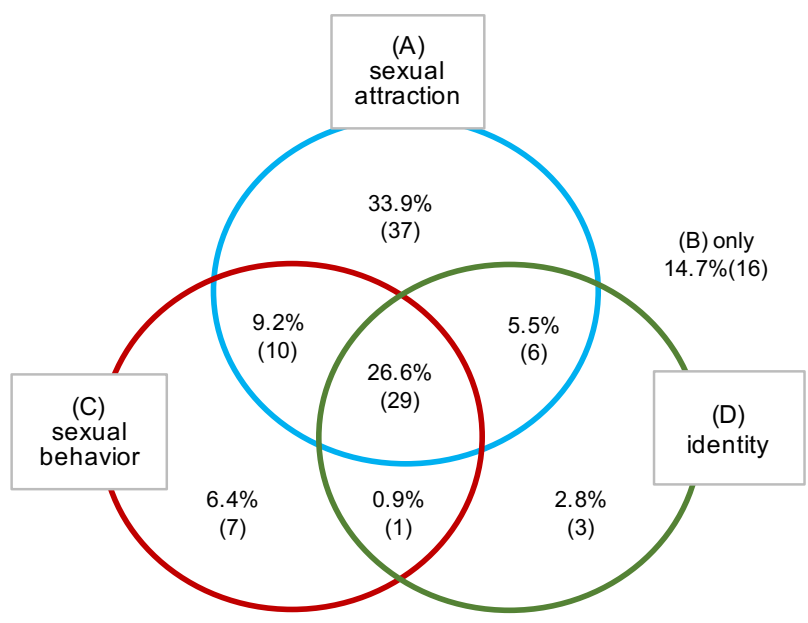

Figure 1.2 Interrelation of components of same-sex sexuality among cisgender men, Osaka City Residents' Survey, 2019:

(A) sexual attraction, (C) sexual behavior, and (D) sexual orientation identity for 109 cisgender men (6.3\% of the total 1742) who report same-sex sexuality in any of the four components (A, B, C or D)

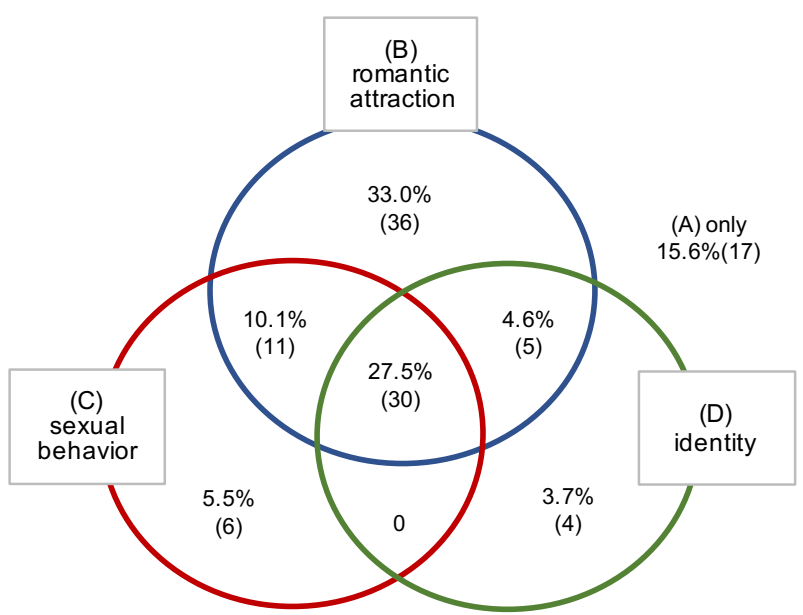

Figure 2.2 Interrelation of components of same-sex sexuality among cisgender men, Osaka City Residents' Survey, 2019:

(B) romantic attraction, (C) sexual behavior, and (D) sexual orientation identity for 109 cisgender men (6.3\% of the total 1742) who report same-sex sexuality in any of the four components $(A, B, C$ or $D)$ 


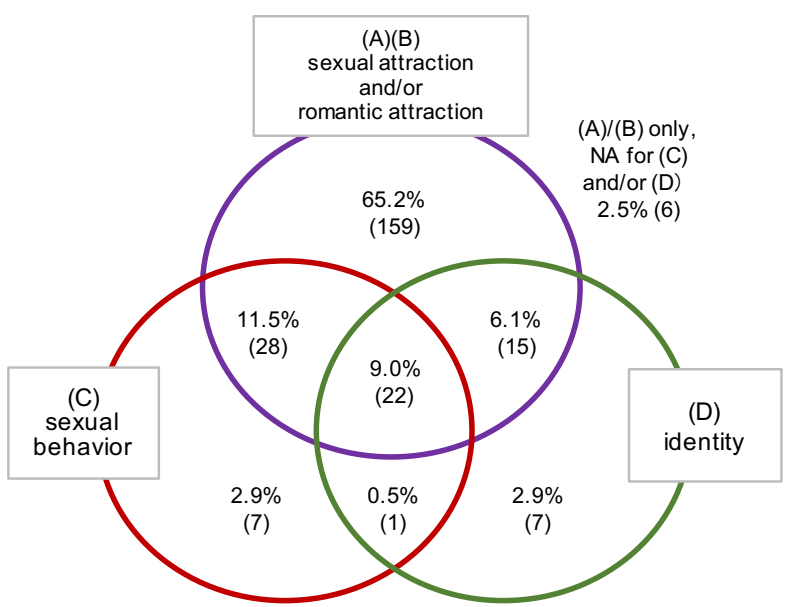

Figure 3.1 Interrelation of components of same-sex sexuality among cisgender women, Osaka City Residents' Survey, 2019: (A) sexual attraction and/or (B) romantic attraction, (C) sexual behavior, and (D) sexual orientation identity for 244 cisgender women (9.8\% of the total 2497$)$ who report same-sex sexuality in any of the four components $(A, B, C$ or $D)$

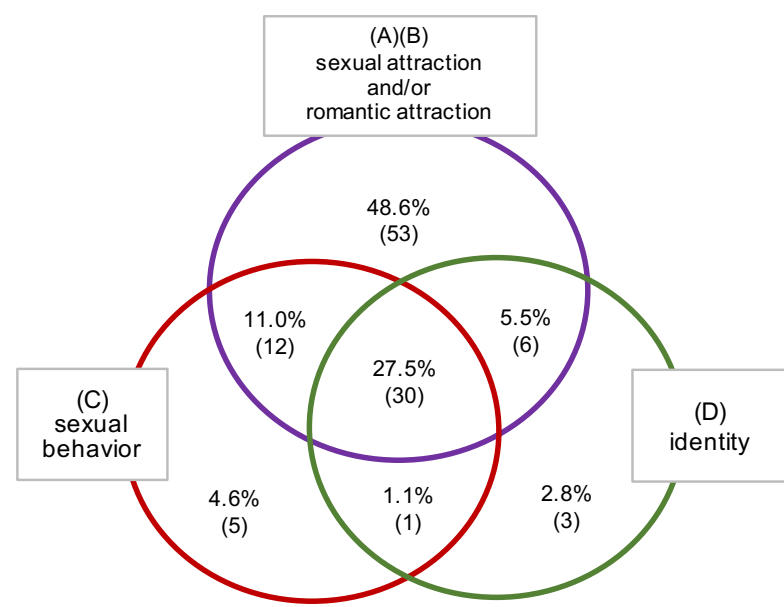

Figure 3.2 Interrelation of components of same-sex sexuality among cisgender men, Osaka City Residents' Survey, 2019: (A) sexual attraction and/or (B) romantic attraction, (C) sexual behavior, and (D) sexual orientation identity for 109 cisgender men $(6.3 \%$ of the total 1742$)$ who report same-sex sexuality in any of the four components (A, B,C or D)

\section{Dimensions of the Asexual Spectrum}

Table 1 shows that $1.0 \%$ of cisgender women and $0.2 \%$ of cisgender men identify as asexual. However, there are other ways to describe the diverse asexual spectrum.

First, we estimate the proportion of those who may be classified as aromantic asexual (those who have neither romantic attraction nor sexual attraction). The results indicate that $1.6 \%$ (70 people) of all respondents-2.1\% (54 people) of females at birth and $0.9 \%$ (16 people) of males at birth—did not report either romantic attraction or sexual attraction ${ }^{8}$. Second, we estimate the proportion of those who may be classified as romantic asexual (those who have romantic attraction but do not have sexual attraction). The results indicate that $1.3 \%$ (56 people) of all

8 When the sexual orientation measures for the recent five years are used, $7.1 \%$ (305 people) of the whole respondents- $10.3 \%$ (259 people) of females at birth and $2.6 \%$ (46 people) of males at birth—do not report either romantic attraction or sexual attraction. 
respondents $-1.8 \%$ (46 people) of females at birth and $0.6 \%$ (10 people) of males at birth — have romantic attraction but do not have sexual attraction ${ }^{9}$. Third, we describe sexual behavior among those who do not have sexual attraction and those who have sexual attraction. Among 127 respondents who did not report the presence of sexual attraction, $60.6 \%$ (77 people) reported that they have never had sex and 38.6\% (49 people) reported otherwise. Among 4,080 respondents who reported the presence of sexual attraction, 5.0\% (206 people) reported that they have never had sex and $94.3 \%\left(3,848\right.$ people) reported otherwise ${ }^{10}$.

Much like measuring other sexualities (Mishel 2019), these results indicate that the prevalence of asexual population depends on the definition of asexuality, such as absence of sexual attraction and asexual identity (Hinderliter 2009), or absence of sexual and romantic attraction, which has been historically used in the Japanese asexual community. Also, the findings indicate that when assessing sexual/romantic attraction, it is important to specify the appropriate time span as using lifetime sexual/romantic attraction and using recent sexual/romantic attraction yield different results.

9 When the sexual orientation measures for the recent five years are used, $1.2 \%$ (52 people) of the whole respondents $-1.8 \%$ (45 people) of females at birth and $0.4 \%$ ( 7 people) of males at birthhave romantic attraction but do not have sexual attraction.

10 When the sexual orientation measures for the recent five years are used, among 360 respondents who did not report the presence of sexual attraction in the last five years, $65.0 \%$ (234 people) reported that they have never had sex and 33.1\% (119 people) reported otherwise. Among 3,832 respondents who reported the presence of sexual attraction in the last five years, 10.4\% (398 people) reported that they have never had sex and $89.1 \%(3,415$ people $)$ reported otherwise. 


\section{$\underline{\text { Discussion }}$}

While there is an increasing number of quantitative studies examining the intersections among multiple aspects of sexual orientation with the availability of representative data, most of these studies use data from Western countries, limiting the generalizability of their findings outside of the Western socio-cultural contexts. Therefore, this paper uses data from the Osaka City Residents' Survey, the first population-based survey in Japan with detailed questions about multiple aspects of sexual orientation, to describe the relationship among various dimensions of sexual orientation such as sexual orientation identity, sexual attraction, romantic attraction, and sexual behavior. In addition to the fact that this dataset comes from Japan, this survey also includes questions to assess the lack of sexual attraction and romantic attraction as well as the lack of sexual behavior. Moreover, this is a unique survey in which the question for sexual orientation identity includes categories such as “asexual," "Don’t want to decide, haven’t decided."

Overall, some of our findings are similar to the patterns observed in previous studies, while other findings are different from those found in previous studies. First, our data numerically support the difficulty of identifying as lesbian in Japanese society argued by lesbian studies scholars in Japan (Kamano 2005; Horie 2015). Compared to women who identify as lesbian (0.2\%), more women identify as bisexual (1.6\%) or asexual (1.0\%). Discussing how difficult it is to express lesbian's desire and subjectivity, Sugiura (2015:8) writes, “men's sexual desire is considered as 
'strong' and 'active,' while women's sexual desire is considered as 'thin' and 'passive"” in contemporary Japanese society. Under this situation of extreme aversion toward women's sexual subjectivity, women may find it difficult to have any sexual desire, let alone same-sex sexual desire, because women, in general, are not supposed to be outspoken about their sexuality. Our analysis of sexual attraction also supports this argument as more women respondents reported no lifetime sexual attraction than men respondents.

Second, our analysis suggests that the response category 'Don't want to decide, haven't decided," which was originally created with the intent of providing a choice for respondents whose sexual orientation identity is questioning, queer, or some other sexual minority category, may have been selected by heterosexual respondents who do not have a "heterosexual" identity. There are likely to be sexual minority respondents who chose this category, but the findings indicate some of those who selected this category are likely to be heterosexual from their sexual attraction, romantic attraction, and sexual behavior. While some lesbian, gay, bisexual, and transgender organizations in Japan such as the Pride House Tokyo use the results of the Osaka City Residents' Survey to claim that 8.2 percent of the population are sexual/gender minorities, counting as sexual minorities those who fall into the category of "Don't want to decide, haven't decided" (Pride House Tokyo 2019), our analysis shows that treating everyone who selected "Don't want to decide, haven't decided" as sexual minorities may lead to an overestimation of the size of the sexual 
minority population. Future research should investigate this issue by conducting additional methodological studies such as large-scale web surveys to better understand who selects this category and what they mean when selecting "Don't want to decide, haven't decided."

Third, the proportion of heterosexual-identified men who have sex with men is lower than that found in research conducted in the United States. Unlike the United States where there is a strong connection between masculinity and heterosexuality among men (Silva 2017), there are higher expectations for women to be feminine than there are for men to be masculine and both women and men score higher in feminine than masculine characteristics in Japan (Sugihara and Katsurada 2000). It is suggested that men who engage in same-sex behavior in Japan may be comparably less likely to be the object of social sanction even if they identified as gay or bisexual than it would be the case in the United States. In other words, it may be said that the social pressure for men to be masculine in Japan is less severe than in the United States. However, at the same time, it should be noted that the development of a stable gay identity in Japan is hindered by the limited development of identity-based sexual minority movements (Kazama and Kawaguchi 2010). Future research should carefully examine what is behind these patterns, as there is virtually no sociological research on straight-identified men who engage in sex with men in Japan.

Fourth, this study analyzes asexualities and reports that $1.0 \%$ of women and $0.2 \%$ of men identify as asexual, $2.1 \%$ of those assigned female and $0.9 \%$ of those assigned male at birth may 
be classified as aromantic asexual, and $1.8 \%$ of those assigned female and $0.6 \%$ of those assigned male at birth may be classified as romantic asexual. All this illustrates the diversity of the asexual spectrum. Most previous studies do not have an identity-based measure of asexuality and often utilize residual categories as an imperfect measure of asexual identity (for example, Poston and Baumle 2010). Studies that fully incorporate multiple aspects of asexualities tend to rely on nonrandom surveys, rendering the findings largely ungeneralizable (for example, Carroll 2019). This paper builds upon these important studies to use unique population-based survey data that contain detailed information on the asexual spectrum collected in Japan.

However, this paper faces some limitations. One major limitation is that the findings from the dataset employed in this study can only be generalizable to Osaka City. Given that Osaka is the third-largest city in Japan, it is likely that there are more respondents who report non-normative forms of sexuality than the national average. Moreover, the number of sexual minorities in this dataset is small, making it difficult to use statistical inference techniques. It is imperative for future research projects to conduct surveys on the national level with an adequate sample size that allows for statistical analysis on various aspects of sexual orientation. More research on the diversity of the transgender population is also needed. In the United States, Doan (2016) draws on various U.S. statistics to estimate that the proportion of transgender people in the United States using a broad definition of transgender and arrives at the figure of $2.91 \%$, while a traditional estimate calculated 
from the same study was $0.65 \%$. In Japan, Iwamoto et al. (forthcoming) use an online panel survey $(n=30,000)$ and estimate that the proportion of respondents who are classified as transgender ranges from $0.35 \%$ to $2.00 \%$. The former figure is calculated from a definition of transgender as those who choose the opposite gender to their sex on the family register at birth as their gender identity, whereas the latter classifies as transgender those who choose any gender that is different from their sex on the family register at birth as their gender identity ${ }^{11}$.

Our study constitutes the first step to developing a theory of the diversity of nonnormative sexualities sensitive to cross-cultural differences. The richness of the detailed information on multiple aspects of sexual orientation from the survey and the rareness of the nonWestern data employed in this study should counterbalance the limitations mentioned above. We argue that demographic research examining dimensions of sexuality should be sensitive to distinct socio-cultural contexts and histories of sexuality to better understand how patterns of sexual

${ }^{11}$ Following the idea that gender is a spectrum, the survey includes six gender identity categories (man, somewhat man, somewhat woman, woman, X-gender/neuter/agender, not sure/other). Those who did not indicate their gender identity were not included in the proportion of transgender people. For the estimate using the broad definition of transgender, those whose sex on the family register at birth is male and gender identity is somewhat man, as well as those whose sex on the family register at birth is female and gender identity is somewhat woman, were not counted as transgender. 
orientation may vary in more complex ways than has been hitherto understood from studies developed in certain limited cultural contexts. 


\section{References}

Badgett, M. V. Lee. 2007. “Discrimination Based on Sexual Orientation: A Review of the Literature in Economics and beyond." Pp. 19-43 in Sexual Orientation Discrimination: An International Perspective, edited by M. V. L. Badgett and J. Frank. New York: Routledge.

Budnick, Jamie. 2016. “'Straight Girls Kissing'?: Understanding Same-Gender Sexuality beyond the Elite College Campus." Gender \& Society 30(5):745-68.

Carroll, Megan. 2019. "Asexuality as the Next Frontier in Sociological Research on Sexualities." Presented at the Annual Meeting of the American Sociological Association, August 13, New York, NY. Retrieved February 5, 2020 (https://osf.io/tz9p7/).

Conron, Kerith J., Matthew J. Mimiaga, and Stewart J. Landers. 2010. “A Population-Based Study of Sexual Orientation Identity and Gender Differences in Adult Health." American Journal of Public Health 100(10):1953-60.

De Cuypere, G., M. Van Hemelrijck, A. Michel, G. Heylens, R. Rubens, P. Hoebeke, and S. Monstrey. 2006. "Prevalence and Demography of Transsexualism in Belgium." European Psychiatry 22(3):137-41.

Dentsu. 2019. "Dentsu Diversity Lab Conducts "LGBT Survey 2018”: LGBT Segment 8.9\%, “LGBT” Penetration Rate Nearly 70\%.” Dentsu, January 10. Retrieved February 5, 2020 (https://www.dentsu.co.jp/news/sp/release/2019/0110-009728.html).

Doan, Petra L. 2016. “To Count or Not to Count: Queering Measurement and the Transgender Community." Women's Studies Quarterly 44(3/4):89-110.

Dulko, S. and C. Imielinski. 2004. "The Epidemiology of Transsexualism in Poland.” Journal of Psychosomatic Research 56(6):637. 
Faure, Bernard. 1998. The Red Thread: Buddhist Approaches to Sexuality. Princeton: Princeton University Press.

Galupo, M. Paz, Shane B. Henise, and Nicholas L. Mercer. 2016. “"The Labels Don’t Work Very Well': Transgender Individuals' Conceptualizations of Sexual Orientation and Sexual Identity.” International Journal of Transgenderism 17(2):93-104.

Gates, Gary J. 2011. 'How Many People Are Lesbian, Gay, Bisexual, and Transgender?” Retrieved February 5, 2020 (https://williamsinstitute.law.ucla.edu/wpcontent/uploads/Gates-How-Many-People-LGBT-Apr-2011.pdf).

Geary, Rebecca S., Clare Tanton, Bob Erens, Soazig Clifton, Philip Prah, Kaye Wellings, Kirstin R. Mitchell, Jessica Datta, Kirsten Gravningen, Elizabeth Fuller, Anne M. Johnson, Pam Sonnenberg, and Catherine H. Mercer. 2018. "Sexual Identity, Attraction and Behaviour in Britain: The Implications of Using Different Dimensions of Sexual Orientation to Estimate the Size of Sexual Minority Populations and Inform Public Health Interventions." PLOS ONE 13(1):e0189607.

Godlewski, Julian. 1988. "Transsexualism and Anatomic Sex Ratio Reversal in Poland.” Archives of Sexual Behavior 17(6):547-8.

Goldberg, Abbie E., JuliAnna Z. Smith, and Maureen Perry-Jenkins. 2012. “The Division of Labor in Lesbian, Gay, and Heterosexual New Adoptive Parents.” Journal of Marriage and Family 74(4):812-28.

Hinderliter, Andrew C. 2009. "Methodological Issues for Studying Asexuality." Archives of Sexual Behavior 38(5):619-21.

Hiramori, Daiki, and Saori Kamano. 2020. “Asking about Sexual Orientation and Gender Identity in Japan: Case Report on the Osaka City Residents' Survey and Related Preparatory 
Studies." To be presented at the Annual Meeting of the Population Association of America, April 23, Washington, DC. Retrieved March 4, 2020

(https://doi.org/10.31235/osf.io/w9mjn).

Horie, Yuri. 2006. "Possibility and Limitation of 'Lesbian Continuum': The Case of a Protestant Church in Japan." Pp. 145-159 in "Lesbians" in East Asia: Diversity, Identities, and Resistance, edited by D. Khor and S. Kamano. Binghamton: Harrington Park Press. Horie, Yuri. 2015. Lesbian Identities. Kyoto, Japan: Rakuhoku Shuppan. In Japanese.

Human Rights Watch. 2018. “Tokyo: New Law Bars LGBT Discrimination: Olympics-Inspired Act Should Spur Japanese National Legislation.” Retrieved February 5, 2020 (https://www.hrw.org/news/2018/10/05/tokyo-new-law-bars-lgbt-discrimination).

Iwamoto, Takeyoshi, Mikiko Takahashi, Akiko Hino, Maki Oide, and Yuki Koike. Forthcoming. "Workplace Environment of Transgender People, and Attitudes toward and Patterns of Restroom Use." Journal of the Japanese Society of Gender Identity Disorder. In Japanese. Japan Times. 2019. "In first, Ibaraki Prefecture to Issue Partnership Certificates for LGBT Couples from July.” Japan Times, June 24. Retrieved February 5, 2020 (https://www.japantimes.co.jp/news/2019/06/24/national/first-ibaraki-prefecture-issuepartnership-certificates-lgbt-couples-july/).

Kamano, Saori. 2005. "Entering the Lesbian World in Japan: Debut Stories." Pp. 11-30 in Lesbian Communities: Festivals, RVs, and the Internet, edited by E. Rothblum and $\mathrm{P}$. Sablove. Binghamton: Harrington Park Press.

Kamano, Saori, Yasuyo Koyama, Yoshimi Chitose, Kana Fuse, Masakazu Yamauchi, Takeyoshi Iwamoto, Hiromi Fujii, Hitoshi Ishida, Daiki Hiramori, and Takashi Yoshinaka. 2019. “"Survey on Diversity of Work and Life, and Coexistence among the Residents of Osaka 
City': Selected Preliminary Results and Q\&A." Journal of Population Problems 75(3):24853. In Japanese.

Kazama, Takashi, and Kazuya Kawaguchi. 2010. Homosexuality and Heterosexuality. Tokyo, Japan: Iwanami Shoten. In Japanese.

Khor, Diana. 2010. "The Foreign Gaze? A Critical Look at Claims about Same-Sex Sexuality in Japan in the English Language Literature." Gender and Sexuality 5:45-59.

Klawitter, Marieka. 2015. "Meta-Analysis of the Effects of Sexual Orientation on Earnings." Industrial Relations: A Journal of Economy and Society 54(1):4-32.

Laumann, Edward O., John H. Gagnon, Robert T. Michael, and Stuart Michaels. 1994. The Social Organization of Sexuality: Sexual Practices in the United States. Chicago: The University of Chicago Press.

Leupp, Gary P. 1995. Male Colors: The Construction of Homosexuality in Tokugawa Japan. Berkeley: University of California Press.

Lunsing, Wim. 2001. Beyond Common Sense: Sexuality and Gender in Contemporary Japan. New York: Kegan Paul.

Mclelland, Mark. 2000. "Is There a Japanese ‘Gay Identity’?" Culture, Health \& Sexuality 2(4):459-72.

McLelland, Mark. 2005. Queer Japan from the Pacific War to the Internet Age. Lanham: Rowman \& Littlefield Publishers.

Mishel, Emma. 2019. "Intersections between Sexual Identity, Sexual Attraction, and Sexual Behavior among a Nationally Representative Sample of American Men and Women." Journal of Official Statistics 35(4):859-84. 
Mitsuhashi, Junko. 2008. Male-to-Female Cross-Dressing and the Japanese. Tokyo, Japan: Kodansha. In Japanese.

Mitsuhashi, Junko. 2012. "The reasons why there are many FtM (Female to Male) people in Japan are...." Zokuzoku Tasogare Nikki Blog. Retrieved February 5, 2020 (http://junkomitsuhashi.blog.so-net.ne.jp/2012-10-19-1). In Japanese.

Mize, Trenton D. 2016. "Sexual Orientation in the Labor Market.” American Sociological Review 81(6):1132-60.

Mollborn, Stefanie and Bethany Everett. 2015. "Understanding the Educational Attainment of Sexual Minority Women and Men." Research in Social Stratification and Mobility 41:4055.

Nijiiro Diversity and the Center for Gender Studies at International Christian University. 2020. The Report of niji VOICE 2019. Retrieved February 5, 2020 (https://nijiirodiversity.jp/nijivoice2019/). In Japanese.

Oshima, Yoshitaka, and Sato Toshiki. 2016. "Medical Consultation of Gender Dysphoria and Population Prevalence.” Kokoro no Kagaku 189:28-32. In Japanese.

Pew Research Center. 2013. "The Global Divide on Homosexuality: Greater Acceptance in More Secular and Affluent Countries." Retrieved February 5, 2020 (http://www.pewglobal.org/2013/06/04/the-global-divide-on-homosexuality/).

Pflugfelder, Gregory M. 1999. Cartographies of Desire: Male-Male Sexuality in Japanese Discourse, 1600-1950. Berkeley: University of California Press.

Poston, Dudley L., and Amanda Baumle. 2010. "Patterns of Asexuality in the United States." Demographic Research 23:509-30. 
Pride House Tokyo. 2019. Sports for Everyone. Tokyo, Japan: Pride House Tokyo. Retrieved February 5, 2020 (http://pridehouse.jp/assets/img/handbook/pdf/sports_for_everyone.pdf).

Rothblum, Esther D., Evan A. Krueger, Krystal R. Kittle, and Ilan H. Meyer. 2019. “Asexual and Non-Asexual Respondents from a U.S. Population-Based Study of Sexual Minorities." Archives of Sexual Behavior. Retrieved February 5, 2020 (https://doi.org/10.1007/s10508019-01485-0).

Saewyc, Elizabeth M., Greta R. Bauer, Carol L. Skay, Linda H. Bearinger, Michael D. Resnick, Elizabeth Reis, and Aileen Murphy. 2004. "Measuring Sexual Orientation in Adolescent Health Surveys: Evaluation of Eight School-Based Surveys.” Journal of Adolescent Health 35(4):345.e1-345.e15.

Schnabel, Landon. 2018. "Sexual Orientation and Social Attitudes.” Socius 4:1-18.

Shimizu, Akiko. 2007. "Scandalous Equivocation: A Note on the Politics of Queer Self-Naming." Inter-Asia Cultural Studies 8(4):503-16.

Silva, Tony. 2017. "Bud-Sex: Constructing Normative Masculinity among Rural Straight Men That Have Sex With Men." Gender \& Society 31(1):51-73.

Sugihara, Yoko, and Emiko Katsurada. 2000. "Gender-Role Personality Traits in Japanese Culture." Psychology of Women Quarterly 24(4):309-18.

Sugiura, Ikuko. 2015. "Discourses of 'Female Homosexuality': Advances and Issues in Historical Research." Bulletin of the Faculty of Human Studies, Wako University 8:7-26. In Japanese.

Sexual Minority Assessment Research Team (SMART). 2009. Best Practices for Asking Questions about Sexual Orientation on Surveys. Los Angeles, CA: The Williams Institute. Ward, Jane. Not Gay: Sex between Straight White Men. New York: New York University Press. 